\title{
The Tensile Behavior of Kevlar-29 Fibers
}

\author{
A. Tejeda-Ochoa, ${ }^{* * *}$ J.A. García-Estrada, ${ }^{* *}$ C.A. Herrera-Ramírez, ${ }^{* * *}$ W. Antúnez-Flores, ${ }^{*}$ R. \\ Martínez-Sánchez, ${ }^{*}$ and J.M. Herrera-Ramírez* \\ * Centro de Investigación en Materiales Avanzados (CIMAV), Laboratorio Nacional de \\ Nanotecnología, Miguel de Cervantes No.120, Chihuahua, Chih., México 31109. \\ ** Instituto Tecnológico de Chihuahua (ITCH), Av. Tecnológico No. 2909, Chihuahua, Chih., \\ México 31310. \\ *** Escuela Superior de Ingeniería Mecánica y Eléctrica (ESIME)-Unidad Culhuacán, Av. Santa \\ Ana No. 1000, Col. San Francisco Culhuacán, Del. Coyoacán, México, D.F., México 04430.
}

Kevlar is an organic fiber (poly-para-phenylene-terephthalamide) in the aromatic polyamide family, produced by DuPont de Nemours [1]. It has a unique combination of high strength, high modulus, toughness and thermal stability. Its remarkable properties are mainly related to the structure developed during the spinning process [2]. It was developed for demanding industrial and advancedtechnology applications. In this work, single Kevlar-29 fibers have been subjected to tensile tests at room temperature using a Universal Fiber Tester developed originally by Bunsell et al. [3], equipped with a load cell of $250 \mathrm{~g}$ calibrated from 0 to $100 \mathrm{~g}$, with a precision of $0.01 \mathrm{~g}$. The specimen gauge length was $30 \mathrm{~mm}$ and the fiber was gripped between two sets of jaws. Data acquisition used a PC linked to the fiber tester via a National Instrument interface card and WinATS 6.2 software from Sysma. In order to normalize the stress, the diameter of each fiber was systematically measured before each test by using a Mitutoyo LSM-500S laser apparatus, with an accuracy of $0.01 \mu \mathrm{m}$.

The tensile stress-strain curves of Kevlar-29 fibers were acquired, which remain almost linear up to failure. The mechanical properties were calculated from these curves, whose values are shown in Table 1 together with the diameter; 30 fibers were broken and mean properties were determined. The standard deviation indicates there is considerable variability in the strength of these fibers. The surface appearance of the untested Kevlar-29 fibers in the scanning electron microscope is smooth, although some striations have been observed (Fig. 1a). The tensile fracture morphology was similar for all the fibers tested (Figs. 1b-e); this complex morphology is due to the structure of Kevlar-29, being highly anisotropic with a low transverse strength leading to splitting upon failure under tensile loading condition [2]; the origin of the splitting may be as a result of stress concentrations at flaws or inside the fibers. Fig. 1e shows the presence of a fibrillar structure. Due to the severe rupture during the solicitation, local heating has been seen in some parts of the fibers, which suggests that melting can occur (Fig. 1f). Fig. 1g displays a micrograph that reveals the existence of a "pleated" structure shown as a series of transverse bands. This radial-sheet structure consists of alternated bands in each sheet arranged at approximately equal but opposite angles to form pleats, as reported elsewhere [2].

\section{References}

[1] www.dupont.com, Technical Guide of Kevlar Aramid Fiber.

[2] A.R. Bunsell, Handbook of tensile properties of textile and technical fibres, 1st ed., Woodhead Publishing Limited, Cambridge, 2009.

[3] A.R. Bunsell, J.W.S. Hearle and R. Hunter, J. Phys. E 4 (1971) 868.

[4] This research was supported by FOMIX CONACYT-Chihuahua under the project 147982. ATO was supported as an undergraduated student by Red de Nanociencias y Nanotecnología. 
TABLE 1. Mechanical properties of the Kevlar-29 fibers.

\begin{tabular}{|l|r|}
\hline Tensile strength $(\mathrm{GPa})$ & $3.04 \pm 0.31$ \\
\hline Breaking strain $(\%)$ & $3.40 \pm 0.36$ \\
\hline Young's modulus $(\mathrm{GPa})$ & $83.78 \pm 7.12$ \\
\hline Diameter $(\mu \mathrm{m})$ & $12.84 \pm 0.69$ \\
\hline
\end{tabular}
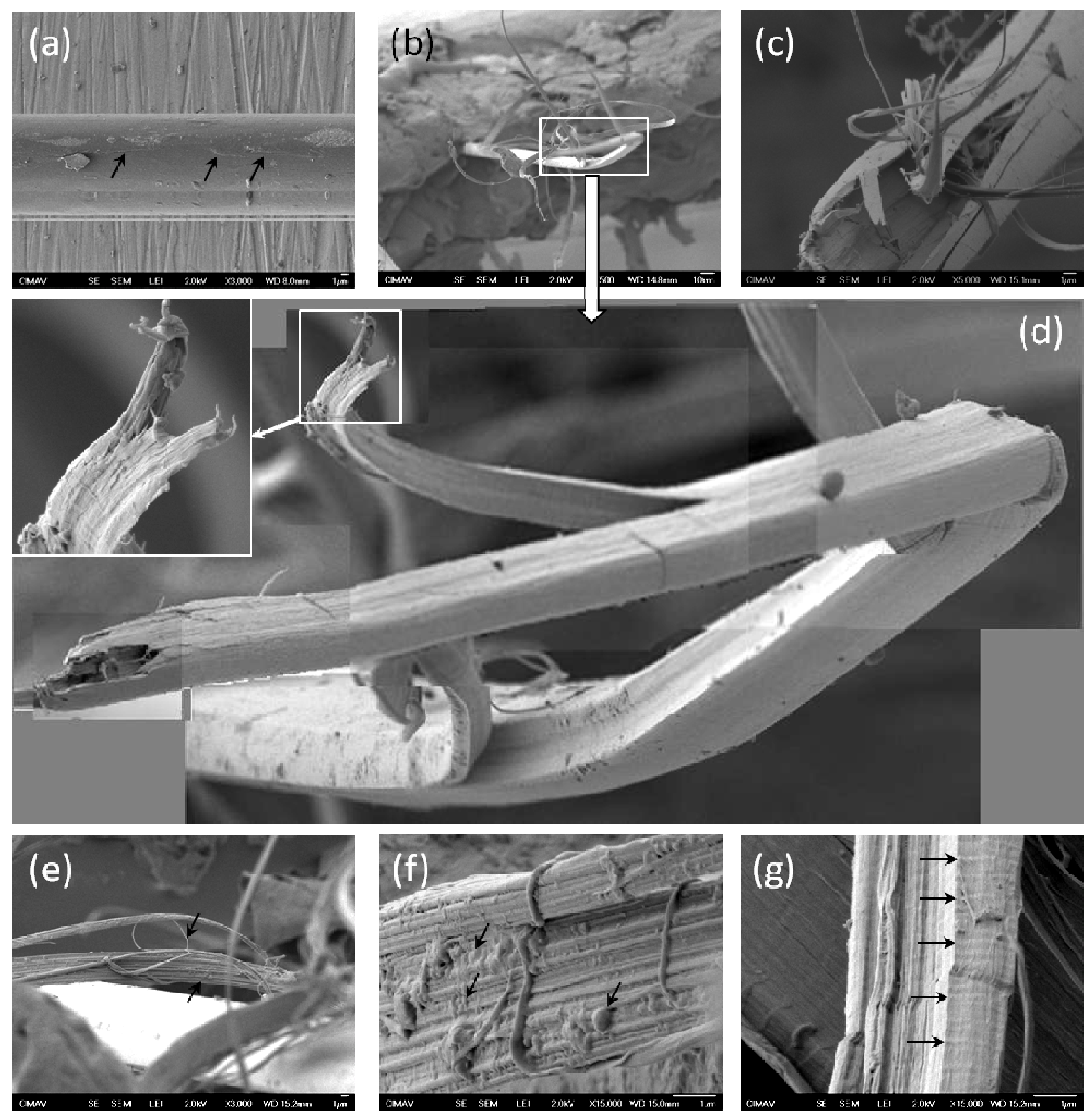

FIG. 1. (a) SEM micrographs showing that Kevlar-29 fibers are smooth cylinder with some flaws (indicated by arrows). (b-e) The tensile fracture morphology shows severe splitting in all the samples tested. (e) Fibrillar structure. (f) Melted parts. (g) Pleated structure. 